\title{
Action of Cholesterol-Loaded Cyclodextrin on Viability of Ram Semen
}

\author{
Juliano Pianowski Marques Silva', André Felipe Berto de Almada', Jonathan Soares de Lima', \\ Carlos Renato de Freitas Guaitolini', André Maciel Crespilho'2, Camila de Paula Freitas Dell'Aqua ${ }^{3}$, \\ José Antônio Dell'Aqua Junior ${ }^{3}$, Danielle Andressa de Oliveira Sestari' \& Rosiara Rosaria Dias Maziero'
}

\begin{abstract}
Background: Studies report that cyclodextrins have the property of carrying cholesterol to the membrane, but in some cases can also remove this cholesterol from the plasma membrane. The mechanism of action of CLC is not well understood, however, it seems to involve sperm protection during the freezing and thawing process. Studies show that its use enhancing increased osmotic tolerance and reduced premature sperm capacitation reaction. In this sense, studies report that cyclodextrins have the property of carrying cholesterol to the membrane, but in some cases can also remove this cholesterol from the plasma membrane. Improvements were reported in the sperm parameters of buffaloes, bulls, stallions and sheep. Ram naturally present less lipids in their membrane, on average $27 \%$, while bulls have $31 \%$, rabbits $62 \%$, and humans $50 \%$. The aim of the present study was to evaluate the use of cholesterol-loaded cyclodextrin (CLC), a commercial diluent, in the kinetics and viability of frozen and thawed ram spermatozoa.

Materials, Methods \& Results: Five ejaculates, from five rams of Dorper breed were collected and divided into three groups: control, $1 \mathrm{mg} \mathrm{CLC}$ and $2 \mathrm{mg}$ CLC. Semen was diluted in different concentrations of CLC $\left(0,1\right.$, and $2 \mathrm{mg} / 120 \times 10^{6}$ spermatozoa), and incubated at room temperature $\left(21^{\circ} \mathrm{C}\right)$ for $10 \mathrm{~min}$. Samples were conditioned in $0.5 \mathrm{~mL}$ straws and incubated at $5^{\circ} \mathrm{C}$ for $4 \mathrm{~h}$, exposed to $\mathrm{LN}_{2}$ vapor for $10 \mathrm{~min}$ and storing a cryogenic container. The parameters as spermatic kinetics, plasma membrane, acrosomal membrane (MPAI, \%), and intracellular levels of superoxide anion $\left(\mathrm{O}_{2}\right)$ were evaluated. Sperm progressive motility (PM), rapid spermatozoa percentage (RAP), linearity (LIN, \%), average path velocity (VAP, $\mu \mathrm{m} / \mathrm{s})$ and MPAI $(\%)$ were more satisfactory with the use of $1 \mathrm{mg}$ compared to $2 \mathrm{mg}(P<0.05)$. In addition, $1 \mathrm{mg}$ CLC showed decreased levels of superoxide anion formation $\left(\mathrm{O}_{2}\right)$, a free radical detrimental to spermatozoa $(P<0.05)$. The use of $2 \mathrm{mg}$ of CLC reduce VAP $(P<0.05)$ and did not have any beneficial effect on the evaluated parameters.

Discussion: Authors did not observe improvement in the parameters of progressive motility when using $1 \mathrm{mg}$ of CLC in goat semen and $2 \mathrm{mg}$ in bull semen with the slow freezing protocol. This differs from our work, as we found that $1 \mathrm{mg}$ of CLC improved the PM parameters, but not at the concentration of $2 \mathrm{mg}$ CLC. Additionally, authors verified that cyclodextrin at $3 \mathrm{mg}$ concentration was effective in protecting the sperm against the deleterious effects of $\mathrm{H}_{2} \mathrm{O}_{2}$. They obtained superior plasma membrane motility, viability, and integrity of the CLC-treated samples compared to the control group. The superoxide anion $\left(\mathrm{O}_{2}\right)$ is a free radical formed from molecular oxygen by the addition of an electron. It is generated spontaneously, mainly in the membrane of the mitochondria, by the respiratory chain and by flavoenzimes, lipoxygenases, and cicloxygenases. In our study, we found a difference between the study group with $1 \mathrm{mg}$ CLC and the control group. Thus, we suggest that CLC may have a beneficial effect in stabilizing the sperm plasma membrane. Use of CLC at a concentration of $1 \mathrm{mg}$ was found to be effective for the improvement of parameters of sperm progressive motility, rapid sperm percentage, and plasma and acrosomal membrane integrity. In addition, the study group with $1 \mathrm{mg}$ of CLC showed decreased levels of superoxide anion formation, a free radical detrimental to spermatozoa.
\end{abstract}

Keywords: ram, semen, cryopreserved, sperm parameters. 


\section{INTRODUCTION}

During cryopreservation process, the sperm membrane undergoes a series of injuries provoked by variations in temperature and the modification of its physical state. These include osmotic and thermal stress, the formation of intracellular ice crystals, and excessive production of reactive oxygen species [7]. These changes promote the destabilization of the sperm lipid membrane [23].

Studies report that young bulls have a higher intact plasma membrane index after thawing compared to adult or senior bulls. This may be associated with the fact that young bulls produce spermatozoa rich in fatty acids compared to older animals [1]. This high concentration of fatty acids confers greater fluidity and flexibility to the plasma membrane, which increases its resistance to osmotic stress, as well as to the oxidative effects caused by cryopreservation [11].

During the cryopreservation process, the semen is initially refrigerated at room temperature, that is, from $37^{\circ} \mathrm{C}$ to $20^{\circ} \mathrm{C}$, which does not seem to cause great damage to the spermatozoa. However, the initial stress occurs when sperm cells pass from body temperature to $5^{\circ} \mathrm{C}$, characteristic of the transition phase, in which the plasma membrane changes from the crystalline liquid state to the gel state. This transition phase occurs both during the freezing process and thawed [11]. By increasing the cholesterol content of the membranes, there is an improvement in the sperm parameters after thawing [4].

Considering reports of improvement in the sperm parameters of frozen/thawed semen when using the cholesterol-loaded cyclodextrin (CLC), and knowing that sheep have naturally low amounts of fatty acids in the sperm membrane, this study aimed to analyze the effects of the addition of CLC in commercial diluent medium during the cryopreservation process of ram spermatozoa.

\section{MATERIALS AND METHODS}

Preparation of the cyclodextrin-loaded cholesterol solution $(C L C)$

The preparation of cholesterol loaded methyl$\beta$-cyclodextrin ${ }^{1}$ was performed according to the methodology of Purdy and Graham [21].

In a pre-sterilized glass tube, $200 \mathrm{mg}$ of cholesterol $(\mathrm{C} 8667)^{1}$ was dissolved in $1 \mathrm{~mL}$ of chloroform, and in another tube, $1 \mathrm{~g}$ of Methyl- $\beta$-cyclodextrin (C4555) 1 was dissolved in $2 \mathrm{~mL}$ of methanol
$\left(\mathrm{CH}_{3} \mathrm{OH}\right)^{1}$. Then, a $0.45 \mathrm{~mL}$ aliquot of the cholesterol and chloroform solution $(\mathrm{C} 2432)^{1}$ was added to the cyclodextrin solution and homogenized to obtain a translucent solution.

The solution was then transferred to a presterilized glass petri dish and the solvents removed by evaporation using hotplate at $40^{\circ} \mathrm{C}$ for a period of $30 \mathrm{~h}$, in a horizontal laminar flow hood. The crystals resulting from the solution were removed from the plate by scraping with a scalpel blade serving as a spatula and stored in a sterile glass tube at room temperature.

The working solution of CLC was prepared by the addition of $50 \mathrm{mg}$ of CLC in $1 \mathrm{~mL}$ of TRIS medium (3.78 g TRIS (hydroxymethyl) aminomethane (252859), $2.11 \mathrm{~g}$ citric acid (251275), $1.22 \mathrm{~g}$ fructose $(1286504)^{1}$ at $37^{\circ} \mathrm{C}$ with subsequent homogenization with the aid of a stirrer.

This solution was packed in $1.5-\mathrm{mL}$ micro centrifuge tubes and kept frozen at $-20^{\circ} \mathrm{C}$, then reheated at $37^{\circ} \mathrm{C}$ in a water bath and homogenized prior to use.

\section{Animals and sample processing}

Harvest and evaluation of fresh semen were carried out in the field, at a private property of the municipality of Umuarama, located at latitude $23^{\circ} 45^{\prime}$ $59^{\prime \prime} \mathrm{S}$ and at a longitude $53^{\circ} 19^{\prime} 30^{\prime \prime} \mathrm{W}$, in the northwest region of the state of Paraná, Brazil.

The diluted samples, packed in freezer vats and refrigerated in a transport carton, were taken to the UNIPAR Animal Reproduction Laboratory, then frozen in a Styrofoam box containing liquid nitrogen (LN2) before storing in cryogenic cylinders.

Sperm evaluations by flow cytometry and by Computer Assisted Semen Analyses (CASA) were carried out at the Faculty of Veterinary Medicine and Animal Science (FMVZ) Unesp, in the Department of Animal Reproduction and Veterinary Radiology located in the city of Botucatu, in the state of São Paulo, at latitude 22 $23^{\circ}$ '09" S and longitude 48 26' 42" West.

Five samples were taken, at weekly intervals, from five animals, totaling 25 collections of Dorper sheep sperm. The animals sampled were sexually mature at ages varying from 12 and 30 months. The samples were collected with the use of an electroejaculator. After collection, the samples were subjectively evaluated by optical microscopy for total motility (MT, $\%)$, vigor (1-5), sperm concentration, and morphology.

Rams considered fit to sample presented a total motility $\geq 80 \%$, vigor 3 (1-5), and a sperm concentra- 
tion $\geq 1$ billion sperm per ejaculate with a percentage of major and minor defects lower than $10 \%$.

For determination of the sperm concentration, $10 \mu \mathrm{L}$ of the ejaculate was diluted in $2 \mathrm{~mL}$ of $10 \%$ formalin saline solution. Sperm count was performed using a hematometric method in a Neubauer chamber.

After the initial screening, each ejaculate was divided into 3 study groups:

1) Control group: Botubov® commercial diluent3;

2) Group 1: Botubov® commercial diluent and $1 \mathrm{mg}$ CLC for each $120 \times 10^{6}$ total spermatozoa;

3) Group 2: Botubov® commercial diluent and $2 \mathrm{mg}$ CLC for each $120 \times 10^{6}$ total spermatozoa.

For each $120 \times 10^{6}$ total spermatozoa, $20 \mu \mathrm{L}$ and $40 \mu \mathrm{L}$ of the prepared solution of cyclodextrin were added in clusters 1 and 2, respectively. After the addition of CLC, the tubes were homogenized and incubated at room temperature for $10 \mathrm{~min}$, allowing for the incorporation of the cholesterol in the membrane wall according to the protocol used by Watson [24].

The sperm concentration in the diluted samples was adjusted to 100 million total spermatozoa per $\mathrm{mL}$ of diluent and filled in $0.5 \mathrm{~mL}$ French straw ${ }^{3}$ previously identified with animal number and collection number. Thus, each vane contained a total of $50 \times 10^{6}$ spermatozoa.

The samples were freeze-dried and placed in a Styrofoam box ${ }^{3}$ previously refrigerated at $5^{\circ} \mathrm{C}$ for 4 h. Then, the freezing curve was performed in liquid nitrogen vapor $\left(\mathrm{LN}_{2}\right)$ by sealing the semen samples in a conventional 40-liter polystyrene box at a fixed distance of $5 \mathrm{~cm}$ from the $\mathrm{LN}_{2}$ level for $10 \mathrm{~min}$. After this period, the vanes were immersed directly into the liquid nitrogen and raked for packaging in cryobiological cylinders.

For the standardization of the post-thawing analyses, the analyses were initiated after a minimum period of 3 days of storage [9].

\section{Sperm analysis after thawing}

For all analysis, the vanes were thawed in a water bath at $46^{\circ} \mathrm{C}$ for $20 \mathrm{~s}$. For post-thaw evaluation, two straws of each ejaculate were used per treatment to remove the effect of the vane.

Post-thaw analysis of sperm kinetics was performed by $\mathrm{CASA}^{2}$ and evaluation of plasma and acrosomal membrane integrity and intracellular level of superoxide anion $\left(\mathrm{O}_{-2}\right)$ by flow cytometry ${ }^{4}$.

\section{Spermatic kinetics}

For the evaluation of spermatic kinetics, five fields were analyzed for each sample with the aid of $\mathrm{CASA}^{2}$.

The parameters evaluated were total sperm motility (MT, \%), progressive sperm motility (MP, \%), average path velocity (VAP, $\mu \mathrm{m} / \mathrm{s}$ ), linearity (LIN, \%), and percentage of spermatozoa with rapid spermatozoa percentage (RAP, \%). The CASA setup used in this experiment is described in Table 1.

For the rapid thermo-resistance test (TTR), two straws from each group of studies were thawed and conditioned in $1.5 \mathrm{~mL}$ microtubes. Samples were kept in a water bath at $46^{\circ} \mathrm{C}$ for $30 \mathrm{~min}$. After this time, evaluations were performed by the CASA system.

Table 1. Methodology of the computerized analysis (CASA) of the spermatic kinetics of ram.

\begin{tabular}{|c|c|}
\hline \multicolumn{2}{|c|}{ Analysis setup: OVINE } \\
\hline Apply sort & $\mathrm{O}$ \\
\hline Frames acquired & 30 \\
\hline Frame rate & $60 \mathrm{~Hz}$ \\
\hline Minimum constrast & 60 \\
\hline Minimum cell size & 60 pixels \\
\hline Minimum static contrast & 1 \\
\hline Straightness (STR), Threshold & $70.0 \%$ \\
\hline Vapcutoff & $30.0 \mu \mathrm{m} / \mathrm{s}$ \\
\hline Prog. Minvap & $40.0 \mu \mathrm{m} / \mathrm{s}$ \\
\hline VSL cutoff & $20.0 \mu \mathrm{m} / \mathrm{s}$ \\
\hline Cell size & 5 pixels \\
\hline Cell intensity & 90 \\
\hline Static head size & 0.10 to 3.40 \\
\hline Static head intensity & 0.30 to 1.50 \\
\hline Static elongation & 8 to 95 \\
\hline Slow cells motile & NO \\
\hline Magnification & 1.95 \\
\hline Video frequency & 60 \\
\hline Bright field & NO \\
\hline LED illumination intensity & 2240 \\
\hline IDENT illumination intensity & 0 \\
\hline Temperature & $38^{\circ} \mathrm{C}$ \\
\hline Chamber depth & $10 \mu \mathrm{m}$ \\
\hline Chamber position & $3.9 \mu \mathrm{m}$ \\
\hline Chamber position $\mathrm{B}$ & $11.8 \mu \mathrm{m}$ \\
\hline Chamber position $\mathrm{C}$ & $16.3 \mu \mathrm{m}$ \\
\hline Chamber position $\mathrm{D}$ & $26.6 \mu \mathrm{m}$ \\
\hline Chamber type & Makler \\
\hline Field selection mode & AUTO \\
\hline IDENT fluorescente option & OFF \\
\hline Integrating time & 1 frames \\
\hline Remote image recall & NO \\
\hline
\end{tabular}


Evaluation of spermatic characteristics by flow cytometry

For flow cytometry analysis, we used the BD LSR Fortessa equipment ${ }^{4}$, equipped with lasers: blue $(488 \mathrm{~nm}, 100 \mathrm{~mW})$, red $(640 \mathrm{~nm}, 40 \mathrm{~mW})$, and violet (405 nm, $100 \mathrm{~mW}$ ). The data were evaluated using the programs BD FACSDiva ${ }^{\mathrm{TM}}$ v6.1 and WinList 6.0 (Verify Software House).

Samples were analyzed at a rate of acquisition of 800 events/second, with 10,000 cells per sample. Cellular debris and particles were excluded from acquisition and analysis by adjustments in threshold and by labeling with Hoechst $33342^{1}(100 \mu \mathrm{g} / \mathrm{mL})$ excited by the violet laser.

\section{Evaluation of the plasma and acrosomal membranes}

The association of propidium iodide probes ${ }^{1}$ (P4170), FITC-PSA (L0770) ${ }^{1}$, and Hoechst 33342 $(1533)^{1}$ was used. For each sample, $200 \mu \mathrm{L}$ of diluted semen in TALP-PVA ${ }^{1}$ at a concentration of $5 \times 10^{6}$ sperm $/ \mathrm{mL}$ were added to $5 \mu \mathrm{L} \mathrm{H3342}(100 \mu \mathrm{g} / \mathrm{mL}), 5$ $\mu \mathrm{L}$ of IP $(50 \mathrm{mcg} / \mathrm{mL})$, and $1 \mu \mathrm{L}$ of FITC-PSA (100 $\mu \mathrm{g} / \mathrm{mL}$ ), and then homogenized and incubated for 15 min in the dark at $37^{\circ} \mathrm{C}$.

\section{Evaluation of superoxide anion generation}

For the evaluation of the production of superoxide $\left(\mathrm{O}_{2}\right)$, intracellular Yo-Pro ${ }^{\circledR}$ association ${ }^{7}$, with markings for cell plasma membrane destabilizing) and Dihydroethidium (DHE, D23107, generation of superoxide anion intracytoplasmic) ${ }^{7}$ was used. Thus, in $500 \mu \mathrm{L}$ of semen diluted in TALP-PVA ${ }^{1}, 25 \mu \mathrm{M}$ of
YP, $20 \mu \mathrm{M}$ of MST, and $2 \mu \mathrm{M}$ of $\mathrm{DHE}^{7}$ were incubated for $20 \mathrm{~min}$ at $37^{\circ} \mathrm{C}$.

\section{Statistical analysis}

Statistical analysis were carried out using the Statistical Analyses System (SAS) ${ }^{8}$. First, the ShapiroWilk test (Proc-Univariate) was used for normal data analysis and the Chi-Square test (Proc-GLM) was used to analyze the homogeneity of the variations. The mean and standard deviation of the experimental groups and their relationships with the study groups were made using analysis of variance (Proc-GLM), adopting a significance level of $5 \%(P<0.05)$

\section{RESULTS}

\section{Spermatic kinetics}

After the freezing/thawing process, the parameters of total motility (MT, \%), progressive motility (MP, \%), average path velocity (VAP, $\mu \mathrm{m} / \mathrm{s}$ ), linearity (LIN, \%), rapid spermatozoa percentage (RAP, \%), total motility post-test of thermoresistance (MT TTR, $\%$ ), and progressive motility post-test of thermoresistance (MP TTR, \%) were evaluated (Table 2).

According to the data presented in Table 2, no difference was observed in the MT parameters between the groups studied. However, the MP and RAP parameters showed that the data obtained by the $1 \mathrm{mg}$ CLC group were superior to the control and $2 \mathrm{mg} \mathrm{CLC}$ groups $(P<0.05)$.

Table 2. Mean values and standard deviation of total motility (TM, \%), progressive motility (PM, \%), average path velocity (VAP, $\mu \mathrm{m}$ / s), linerality (LIN, \%), percentage of rapid sperm (RAP, \%), total motility post-test of thermoresistance (TM, TTR; \%), progressive motile post-test of thermoresistance (PM, TTR, \%), frozen / thawed semen.

\begin{tabular}{cccc}
\hline Parameter & C & Group1 & Group 2 \\
\hline TM $(\%)$ & $46.08 \pm 21.4$ & $58.96 \pm 18.3$ & $47.8 \pm 23.5$ \\
PM $(\%)$ & $21.64 \pm 10.1^{\mathrm{b}}$ & $28.96 \pm 8.6^{\mathrm{a}}$ & $23.84 \pm 11.4^{\mathrm{b}}$ \\
LIN $(\%)$ & $52.04 \pm 8.3$ & $51.08 \pm 9.1$ & $52.4 \pm 5.8$ \\
VAP $\mu \mathrm{m} / \mathrm{s}$ & $58.68 \pm 9^{\mathrm{a}}$ & $59.88 \pm 5.0^{\mathrm{a}}$ & $52.96 \pm 8^{\mathrm{b}}$ \\
RAP $(\%)$ & $30.56 \pm 17.5^{\mathrm{b}}$ & $41.24 \pm 18.8^{\mathrm{a}}$ & $30.818 .8^{\mathrm{b}}$ \\
TM TTR $(\%)$ & $2.84 \pm 5.3$ & $7.84 \pm 10.2$ & $5.2 \pm 9.3$ \\
PM TTR $(\%)$ & $1.24 \pm 3.5$ & $4.08 \pm 7.3$ & $1.92 \pm 3.7$ \\
\hline
\end{tabular}

$\mathrm{C}=$ control, Group 1=1 mg CLC and Group 2= $2 \mathrm{mg}$ CLC. Different lowercase letters on the same line indicate significant difference $(P<0.05)$.

The VAP parameter was lower in the $2 \mathrm{mg}$ CLC group compared to the control and $1 \mathrm{mg}$ CLC groups. However, linearity (LIN, \%), MT post TTR $(\%)$, and PM post TTR (\%) did not show differences between the groups.

\section{Spermatic viability}

In order to evaluate cell viability, the plasma and acrosomal membrane integrity parameters and intracellular level of superoxide anion $\left(\mathrm{O}_{2}\right)$ were verified. The data obtained are presented in Table 3. 
In the evaluation of the integrity of the plasma and acrosomal membranes, it was verified that group 1 presented a higher percentage of intact cells, compared to the control groups, and this result did not present differences when compared to group $2(P<0.05)$.
In the evaluation of the intracellular level of superoxide anion $\left(\mathrm{O}_{2}\right)$, we verified that group 1 was effective in decreasing the formation of this free radical, compared to the control group, while group 2 provided similar data to group 1 and the control.

Table 3. Mean and standard deviation of percentage of intact plasma and acrosomal membranes (MPAI, \%), intracellular level of superoxide anion $\left(\mathrm{O}_{2}^{-}\right)$in the control groups, Group 1 and Group 2.

\begin{tabular}{cccc}
\hline Parameter & $\mathrm{C}$ & 1 & 2 \\
\hline MPAI, $(\%)$ & $54.94 \pm 17.8^{\mathrm{b}}$ & $56.04 \pm 20.8^{\mathrm{a}}$ & $55.86 \pm 18.59^{\mathrm{ab}}$ \\
superoxide anion $\left(\mathrm{O}_{2}^{-}\right)$ & $70.74 \pm 14.9^{\mathrm{a}}$ & $51.63 \pm 17^{\mathrm{b}}$ & $60.45 \pm 2^{\mathrm{ab}}$ \\
\hline $\mathrm{C}=$ control, Group 1= 1 mg CLC and Group 2= 2 mg CLC. Different lowercase letters on the same line indicate significant difference
\end{tabular}

$\mathrm{C}=$ control, Group 1=1 mg CLC and Group 2= $2 \mathrm{mg}$ CLC. Different lowercase letters on the same line indicate significant difference $(P<0.05)$.

\section{DISCUSSION}

Sperm cryopreservation plays an essential role in the preservation of genetic material of endangered species, as it allows for the storage of semen for long periods of time. In addition, it facilitates the management of animals, since they do not need to be transported over long distances, avoiding the stress caused by transportation, as well as avoiding the potential for contagion of sexually transmitted diseases $[10,13]$.

However, despite these advantages, the cryopreservation process causes damage to sperm cells, in particular the plasma membrane. Studies show that, when added to the ejaculate alone, cyclodextrins stimulate the removal of cholesterol from the sperm membrane. However, when they are preloaded with cholesterol, they stimulate the incorporation therein into the cell membranes. This occurs because the cyclodextrins have an internal hydrophobic core and a high affinity for sterols [20].

Thus, several studies have reported improvements in sperm parameters in buffalo [22], bulls [5,26], stallions $[12,17]$ and sheep $[11,15,18]$ after the process of sperm cryopreservation, with the addition of cyclodextrin to the ejaculate.

Authors tested fast freezing protocols using direct freezing (vitrification) of the vane, with $2 \mathrm{~h}$ of refrigeration at $5^{\circ} \mathrm{C}$ and a concentration of $1 \mathrm{mg}$ of CLC in goat semen and $2 \mathrm{mg}$ of CLC in bull semen. They found that rapid freezing, associated with CLC, improved the total motile parameters, both in the semen of the bulls and in the semen of the goats [15], contrary to our study, in which we did not observe improvement in this parameter, with the use of this concentration.
However, when these authors used the slow freezing protocol for both bull and goat ejaculates, they did not observe improvement in total motility parameters, in accordance with the results of the present study.

Other authors did not observe improvement in the parameters of progressive motility when using $1 \mathrm{mg}$ of CLC in goat semen and $2 \mathrm{mg}$ in bull semen with the slow freezing protocol [16]. This differs from our work, as we found that $1 \mathrm{mg}$ of CLC improved the PM parameters, but not at the concentration of 2 mg CLC.

Different concentrations of CLC $(0.5,1,1.5$, 3 , and $6 \mathrm{mg}$ ) were tested in the ejaculate of antelopes (Nanger dama ruficollis). No differences in path velocity values (VAP, $\mu \mathrm{m} / \mathrm{s}$ ) were observed after freezing/ thawing [25]. In the present study, we verified that the concentration of $2 \mathrm{mg}$ impaired sperm velocity, showing lower VAP data when compared to the control group and group 1 (1 mg CLC). High concentrations of cyclodextrin can cause an efflux of cholesterol from the spermatozoa membrane, interfering with the value of VAP [8].

In another work, the linearity (LIN, \%) was altered only with high concentrations of CLC (3 and $6 \mathrm{mg}$ ) [25]. In the present study, when we used a maximum concentration of $2 \mathrm{mg}$ of CLC, we did not observe any interference of this parameter, similar to that reported by these authors.

The CLC used in stall refrigeration protocols of stallions at $5^{\circ} \mathrm{C}$ at 24 and $48 \mathrm{~h}$ were able to interfere with the MT, MP, VAP, and RAP parameters. All parameters evaluated with refrigeration for $24 \mathrm{~h}$, as well as for $48 \mathrm{~h}$, with the use of CLC, contributed to an improvement in seminal quality. Concentrations of 1.5 and $2 \mathrm{mg}$ of CLC were more effective than the 
concentration of $1 \mathrm{mg}$. These authors observed that the concentration of $1 \mathrm{mg}$ of CLC was more effective than the control group (without addition of CLC) [12]. These results differ from our work, in which we used frozen samples of sheep semen and obtained better sperm parameters with the use of $1 \mathrm{mg}$ of CLC compared to $2 \mathrm{mg}$ of CLC.

In a study using fresh sheep semen, authors induced oxidative stress by adding $\mathrm{H}_{2} \mathrm{O}_{2}$ to the ejaculate before incubating for $12 \mathrm{~h}$ at $35^{\circ} \mathrm{C}$. These authors verified that cyclodextrin at $3 \mathrm{mg}$ concentration was effective in protecting the sperm against the deleterious effects of $\mathrm{H}_{2} \mathrm{O}_{2}$. They obtained superior plasma membrane motility, viability, and integrity of the CLC-treated samples compared to the control group [19].

The superoxide anion $\left(\mathrm{O}_{2}^{-}\right)$is a free radical formed from molecular oxygen by the addition of an electron. It is generated spontaneously, mainly in the membrane of the mitochondria, by the respiratory chain and by flavoenzimes, lipoxygenases, and cicloxygenases. It is a small reactive radical and does not have the ability to penetrate the lipid membranes, acting only in the compartment where it is produced [19]. In our study, we found a difference between the study group with $1 \mathrm{mg}$ CLC and the control group. Thus, we suggest that CLC may have a beneficial effect in stabilizing the sperm plasma membrane.

In studies with sheep semen [3] tested the effect of different concentrations (0, 2, 4, and $6 \mathrm{mg}$ ) of CLC added to vitamin $\mathrm{E}$ during cryopreservation and tested their effects on plasma and acrosomal membrane. In the tests performed, no differences in plasma membrane integrity were observed between the control group and the group in which $2 \mathrm{mg}$ of CLC was added. However, the highest concentrations ( 4 and $6 \mathrm{mg}$ of CLC) were harmful to the plasma membrane of spermatozoa. The percentage of sperm cells with the intact acrosome did not differ between the control group and the $2 \mathrm{mg}$ CLC group. Already in the study group with 4 $\mathrm{mg}$ of CLC, we found a decrease in the percentage of sperm cells with an intact acrosome. The group with $6 \mathrm{mg}$ of CLC obtained worse results than the group that received $4 \mathrm{mg}$ of CLC, in terms of percentage of intact acrosssoma.

Altering the integrity of the plasma membrane and acrosome membrane, especially at high concentrations of CLC, can be justified by the efflux of cholesterol that high concentrations of cyclodextrin cause in spermatozoa [8]. In the present study, an improvement in plasma and acrosomal membrane integrity was noted by adding $1 \mathrm{mg}$ of CLC. In the group receiving $2 \mathrm{mg}$ of CLC, no difference was observed in relation to the control group, and in relation to group 1, group 2 did not present any significant differences.

The thermoresistance test (TTR) allows determination of the number of spermatozoa active after the test and the fertilization rate, thus enabling the elimination of inadequate semen samples, that is, those with a final motility lower than $20 \%$ at the end of incubation [14]. However, previous studies have stated that there is no correlation between this test and the pregnancy rate [2]. In the present study, we observed no difference in the TTR between the groups studied.

\section{CONCLUSION}

In conclusion, the use of CLC at a concentration of $1 \mathrm{mg}$ was found to be effective for the improvement of parameters of sperm progressive motility, rapid sperm percentage, and plasma and acrosomal membrane integrity. In addition, the study group with $1 \mathrm{mg}$ of CLC showed decreased levels of superoxide anion formation, a free radical detrimental to spermatozoa. The use of $2 \mathrm{mg}$ of CLC did not have any beneficial effect on the evaluated parameters, with a decrease in the sperm displacement velocity.

\section{MANUFACTURERS}

${ }^{1}$ Sigma Chemical Co. St. Louis, MO, USA.

${ }^{2}$ Hamilton Thorne Research. Beverly, MA, USA.

${ }^{3}$ Botupharma Animal Biotechnology. Botucatu, SP, Brazil.

${ }^{4}$ Becton Dickinson. Mountain View, CA, USA.

${ }^{5}$ IMV® Tecnologies. L'Aigle, Normandy, France.

${ }^{6}$ Life Technologies. Carlsbad, CA, USA.

${ }^{7}$ abcam. Cambridge, UK.

${ }^{8}$ Institute Inc. Cary, NC, USA.

Acknowledgements. University Paranaense (UNIPAR) and Botupharma Biotecnologia Animal for financial support.

Ethical approval. This study was approved by Ethics Committee on Animal Experimentation of the University of Umuarama, Paraná (UNIPAR): protocol n 33704/2017, dated 08/07/2017.

Declaration of interest. The authors report no conflicts of interest. The authors alone are responsible for the content and writing of the paper. 


\section{REFERENCES}

1 Argov-Argaman N., Mahgrefthe K., Zeron Y. \& Roth Z. 2013. Variation in lipid profiles within semen compartments - the bovine model of aging. Theriogenology. 80(7): 712-721.

2 Arruda R.P., Barnabe V.H., Alencar M.M. \& Barnabe R.C. 1992. Avaliação de sêmen congelado de bovinos. Provas lenta e rápida de termo-resistência: efeitos sobre a fertilidade. Brazilian Journal of Veterinary Research and Animal Science. 29(1): 131-137.

3 Benhenia K., Rahab H., Smadi M.A., Benmakhlouf H., Lamara A., Idres T. \& Iguer-Ouada M. 2018. Beneficial and harmful effects of cyclodextrin-vitamin E complex on cryopreserved ram sperm. Animal Reproduction Science. 195: 266-273.

4 Blanch E., Tomás C., Graham J.K. \& Mocé E. 2012. Response of boar sperm to the treatment with cholesterolloaded-cyclodextrins added prior to cryopreservation. Reproduction in Domestic Animals. 47(6): 959-964.

5 Boscarato A.G., Martins L.F., Pinho R.O., Silva Y.F.R.S., Papa F.O. \& Macedo G.G. 2016. Efeito da adição de ciclodextrina carregada com colesterol sobre a qualidade do sêmen congelado/descongelado de touros adultos da raça Nelore. Revista Brasileira de Reprodução Animal. 40(3): 105-110.

6 Bucak M.N., Sarıözkan S., Tuncer P.B., Ulutaş P.A. \& Akçadağ H.İ. 2009. Effect of antioxidants on microscopic semen parameters, lipid peroxidation and antioxidant activities in Angora goat semen following cryopreservation. Small Ruminant Research. 81(2-3): 90-95.

7 Chatterjee S. \& Gagnon C. 2001. Production of reactive oxygen species by spermatozoa undergoing cooling, freezing, and thawing. Molecular, Reproduction and Development: Incorporating Gamete Research. 59(4): 451-458.

8 Choi Y. H. \& Toyoda Y. 1998. Cyclodextrin removes cholesterol from mouse sperm and induces capacitation in a protein-free medium. Biology of Reproduction. 59(6): 1328-1333.

9 Crespilho A.M., Nichi M., Guasti P.N., Freitas-Dell'Aqua C.P., Sá Filho M.F., Maziero R.R. \& Papa F.O. 2014. Sperm fertility and viability following $48 \mathrm{~h}$ of refrigeration: evaluation of different extenders for the preservation of bull semen in liquid state. Animal Reproduction Science. 146(3-4): 126-133.

10 Errandonea N., Fierro S., Viñoles C., Gil J., Banchero G. \& Olivera-Muzante J. 2018. Short term protein supplementation during a long interval prostaglandin-based protocol for timed AI in sheep. Theriogenology. 114: 34-39.

11 Graham J.K. 1996. Cryopreservation of stallion spermatozoa. Veterinary Clinics of North America: Equine Practice. 12(1): 131-147.

12 Hartwig F.P., Lisboa F.P., Monteiro G.A., Maziero R.R.D., Freitas-Dell'Aqua C.P., Alvarenga M.A. \& Dell'Aqua Jr. J.A. 2014. Use of cholesterol-loaded cyclodextrin: An alternative for bad cooler stallions. Theriogenology. 81(2): 340-346.

13 Lone S.A. 2018. Possible mechanisms of cholesterol-loaded cyclodextrin action on sperm during cryopreservation. Animal Reproduction Science. 192: 1-5.

14 Luz S.L.N., Neves J.P. \& Gonçalves P.B.D. 2000. Parâmetros utilizados na avaliação do sêmen congelado ovino para inseminação laparoscópica. Brazilian Journal of Veterinary Research and Animal Science. 37(2): 141-145.

15 Mocé E., Purdy P.H. \& Graham J.K. 2010. Treating ram sperm with cholesterol-loaded cyclodextrins improves cryosurvival. Animal Reproduction Science. 118(2-4): 236-247.

16 Mocé E., Tomás C., Blanch E. \& Graham J.K. 2014. Effect of cholesterol-loaded cyclodextrins on bull and goat sperm processed with fast or slow cryopreservation protocols. Animal. 8(5): 771-776.

17 Moore A.I., Squires E.L. \& Graham J.K. 2005. Adding cholesterol to the stallion sperm plasma membrane improves cryosurvival. Cryobiology. 51(3): 241-249.

18 Motamedi-Mojdehi R., Roostaei-Ali Mehr M. \& Rajabi-Toustani R. 2014. Effect of Different Levels of Glycerol and Cholesterol Loaded Cyclodextrin on Cryosurvival of Ram Spermatozoa. Reproduction in Domestic Animals. 49(1): 65-70.

19 Naseer Z., Ahmad E., Aksoy M., Küçük N., Serin I., Ceylan A. \& Kum C. 2015. Protective effect of cholesterolloaded cyclodextrin pretreatment against hydrogen peroxide induced oxidative damage in ram sperm. Cryobiology. 71(1): 18-23.

20 Navratil A.M., Bliss S.P., Berghorn K.A., Haughian J.M., Farmerie T.A., Graham J.K. \& Roberson M.S. 2003. Constitutive localization of the gonadotropin-releasing hormone $(\mathrm{GnRH})$ receptor to low density membrane microdomains is necessary for GnRH signaling to ERK. Journal of Biological Chemistry. 278(34): 31593-31602. 
21 Purdy P.H. \& Graham J.K. 2004. Effect of cholesterol-loaded cyclodextrin on the cryosurvival of bull sperm. Cryobiology. 48(1): 36-45.

22 Rajoriya J.S., Prasad J.K., Ramteke S.S., Perumal P., Ghosh S.K., Singh M. \& Srivastava N. 2016. Enriching membrane cholesterol improves stability and cryosurvival of buffalo spermatozoa. Animal Reproduction Science. 164: $72-81$.

23 Trevizan J.T., Carreira J.T., Carvalho I.R., Kipper B.H., Nagata W.B., Perri S. H.V. \& de Koivisto M.B. 2018. Does lipid peroxidation and oxidative DNA damage differ in cryopreserved semen samples from young, adult and aged Nellore bulls? Animal Reproduction Science. 195: 8-15.

24 Watson P.F., Morris G.J. \& Clarke A. 1981. The effects of cold shock on sperm cell membranes. In: Effects of low temperatures on biological membranes. New York: Academic Press, pp.189-218.

25 Wojtusik J., Pennington P., Songsasen N., Padilla L.R., Citino S.B. \& Pukazhenthi B.S. 2016. Pretreatment of Addra gazelle (Nanger dama ruficollis) spermatozoa with cholesterol-loaded cyclodextrins improves cryosurvival. Cryobiology. 73(3): 388-395.

26 Yadav H.P., Kumar A., Shah N., Chauhan D.S., Saxena A., Yadav S. \& Swain D.K. 2017. Effect of cholesterol loaded cyclodextrin supplementation on tyrosine phosphorylation and apoptosis like changes in frozen thawed Hariana bull spermatozoa. Theriogenology. 96: 164-171. 